\title{
Prevalence of Thyroids Dysfunction among Saudi Adult Males and Females from (June- September 2016)
}

\author{
*Ahmed Ali Gaffer Ali ${ }^{1}$, Sana Abdalfttah Altahir ${ }^{2}$ \\ ${ }^{1}$ M.S.c Haematology and Blood bank Faculty of Medical Laboratory Sciences, Alzaeim Alazhari University. \\ ${ }^{2}$ M.S.C Microbiology Faculty of Medical Laboratory Sciences, Alneelain University.
}

Received: October 17, 2016; Accepted: October 20, 2016; Published: November 09, 2016

*Corresponding author: Ahmed Ali Gaffer Ali, M.S.c Hematology and blood bank, Faculty of Medical Laboratory Sciences Alzaeim Alazhari University. Sudan.E-mail:ahmedkodab2009@gmail.com

\section{Abstract}

Background: Thyroid disorders are amongst the most prevalent of medical conditions. Their manifestations vary considerably from area to area and are determined principal by the availability of iodine in the diet.

Aim: To determine the prevalence of thyroid dysfunction (hypo and hyperthyroidisms in Saudi adults males and females.

Methods: Total 71 Saudi adults' males and females were Tested for Thyrotropin (TSH) level using direct antigen EIA by fully automated DS2 ELISA system.

Results: We found that prevalence of thyroid dysfunction in overall males and females is $43.6 \%, 40.8 \%$ hypothyrodisms and 2.8 hyperthyroidisms, the prevalence in females separately is $46.03 \% 29 / 63$ cases, $\quad 42.8 \%$ of them hypothyroidisms and 3.17 hyperthyroidism case and in males is $25 \% 2 / 8$ hypothyroidisms and no case of hyperthyroidisms observed

Conclusion: Thyroid dysfunction is highly prevalent in albaha city in females more prevalent than males we recommend more researches in this area with high sample size especially in females.

\section{Introduction}

The thyroid gland plays a vital role in body metabolism,through the production of thyroid hormones, which are known to have important actions in controlling many of the human reproductive functions[1] . Thyroid disorders are amongst the most prevalent of medical conditions. Their manifestations vary considerably from area to area and are determined principal by the availability of iodine in the diet. Epidemiological studies of thyroid dysfunction have limitations, for example the definition of overt hypothyroidism and subclinical hypothyroidism, the selection criteria of the sample used, the influence of age, sex, genetic and environmental factor and the different techniques used for the measurement of thyroid hormones and the relative paucity of incidence data[2].Almost one-third of the world's population lives in areas of iodine deficiency[3]. In areas where the daily iodine intake is below $50 \mu \mathrm{g}$, goitre is usually endemic, and when the daily intake falls below $25 \mu \mathrm{g}$, hypothyroidism is seen. The prevalence of goitre in areas of severe iodine deficiency can be as high as $80 \%$. Populations at particular risk tend to be remote and live in mountainous areas in South-East Asia, Latin America and Central Africa[4] . Iodisation programmes are of proven value in reducing goitre size and in preventing goitre development and cretinism in children. Goitrogens in the diet,such as thiocyanate in incompletely cooked Cassavaor thioglucosides in Brassica vegetables, can explainsome of the differences in prevalence of endemic goitre in areas with similar degrees of iodine deficiency[4]. The prevalence of spontaneous hypothyroidism is between $1 \%$ and $2 \%$, and itis more common in older women and ten times more common in women than in men. ${ }^{2}$ In the Whickham survey, the prevalence of newly diagnosed overt hypothyroidism was 3 per 1000 women. ${ }^{5}$ The prevalence of previously diagnosed and treated hypothyroidism was 14 per 1000 women, increasing to 19 per 1000 women when possible but unproven cases were included. The overall prevalence in men was less than 1 case per1000. One third had been previously treated by surgeryor radioiodine for thyrotoxicosis. Excluding iatrogenic causes, the prevalence of hypothyroidism was 10 per1000 women, increasing to 15 per 1000 when possible but unproven cases were included. The mean age at diagnosis was 57 years. Other studies in Northern Europe, Japan and the USA have found the prevalence to range between 0.6 and 12 per 1000 women and between 1.3 and 4.0 per 1000 in men investigated .In the Colorado and NHANES III studies, the prevalence of newly diagnosed hypothyroidism was 4 per 1000 and 3 per 1000respectively, $[6,7]$ prevalence of hyperthyroidism in women is between 0.5 and $2 \%$, and is ten times more common in women than in men in iodine-replete communities. In the Whickham survey, the prevalence of undiagnosed hyperthyroidism was 4.7 per 1000 women [5]. Awad Saad Al Shahrani, et.all discuss the prevalence of the thyroid dysfunction in different Arab country region with systemic review of previous research they found that the prevalence of different types of thyroid disease varied 
between the reported studies in Arab world ranging from 6.18 to $47.34 \%$ prevalence of goiter reported by several studies conducted in Arab world, such as Egypt, Algeria and Bahrain with 25.25, 86 and 1.7\%,respectively [8 in Saudi Arabia most of study of thyroid problems done by using thyroid biopsy [8] . Our study area albahah city is a city in the south west of Saudi Arabia, It is the capital of $\mathrm{Al}$ Bahah Region nestled between the resorts of Mecca and Abha the climate in Al-Baha is mild with temperatures ranging between 12 to $23{ }^{\circ} \mathrm{C}$ due to its location at 2,500 meters $(8,200 \mathrm{ft})$ above sea level[9],so high altitude and demand of iron as seen in literature may affect the prevalence of thyroid dysfunction.

\section{Materials and methods}

This was across sectional hospital based study designed to investigate the thyroid dysfunction by estimation of Thyrotropin level (TSH) among Saudi adult males and females to determine the prevalence of hyper and hypothyroidisms in studies population in order to compare the result to other population world wide .all studies population above 18 years who attended to ASHFA MEDICAL COMPELX located in AlBAHAH city during the period June-September 2016 exclude pregnant women from the study and other citizen not live in albahah city or staying short period in albahah city total number of studies population was 71 study participant 63 of them were females and 8 were males. Five $\mathrm{ml}$ of venous blood sample were collected by standard method of blood collection in serum gel tube from each participant to evaluate the thyrotropin level, serum was separated immediately by a fine centrifugation machine and sent for thyroid function test. TSH were quantitatively determined using direct antigen -EIA HUMAN lot 15007 and 16002 respectively ,curve automatically prepared by DS2 ELISA system ,result more than $4 \mathrm{mlU} / \mathrm{L}$ consider as abnormal high result and also result less than $0.3 \mathrm{mlU} / \mathrm{L}$ consider abnormal low results .

\section{Result}

During study period 71 study participant 63 are females and 8 males fig[1] were included in our study, we found that prevalence of thyroid dysfunction in overall males and females is $43.6 \%$ show fig [2], 40.8\%hypothyrodisms and 2.8 hyperthyroidisms, the prevalence in females separately is $46.03 \% 29 / 63$ cases fig [3], $42.8 \%$ of them hypothyroidisms and 3.17 hyperthyroidism case and in males is $25 \% 2 / 8$ fig [4]

Hypothyroidisms and no case of hyperthyroidisms observed.

\section{Discussions}

In this study aimed to detect prevalence of thyroid dysfunction using a serum thyrotrobin level for indicators of hypo and hyperthyroidisms respectively in adults males and females in albahah city we found prevalence of thyroid dysfunction is $43.6 \%$ this is high percent comparing to other population but agreed with some extent with study done in Saudi Arabia population which is $47.43 \%[10]$ all reported of thyroid abnormality were hypothyroidisms with exception of three cases of hyperthyroidisms, predominant of hypothyroidisms manifest females populations with $13.5: 1$ females to male ratio

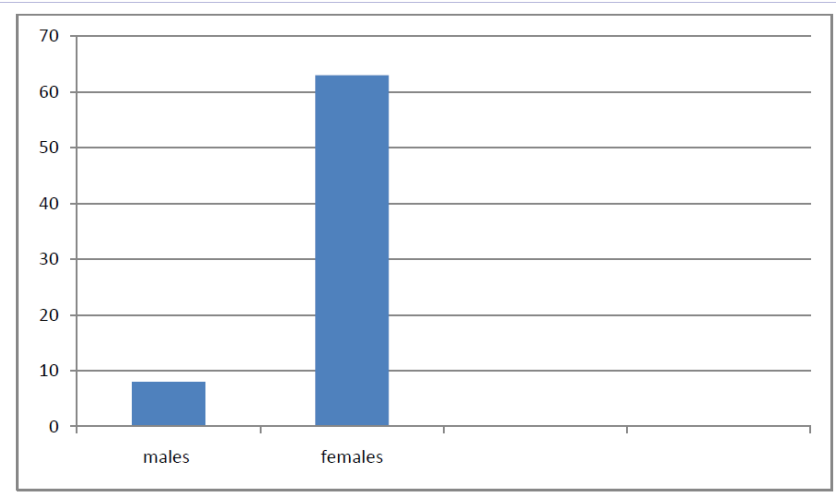

Figure 1: Total number of studies_population.

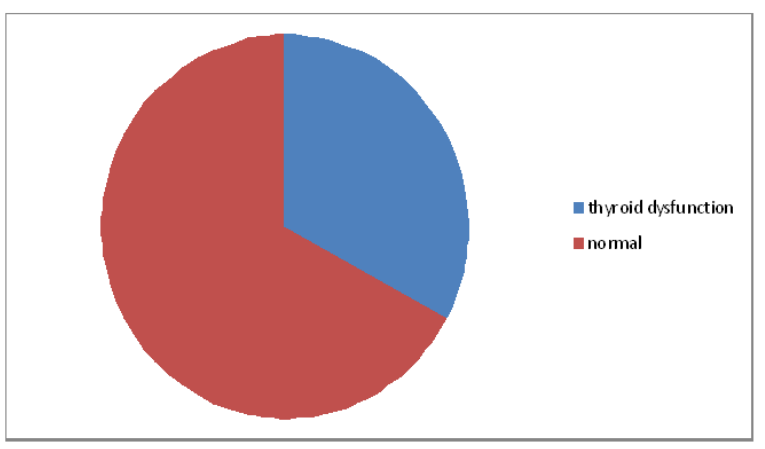

Figure 2: Prevalence Thyroid dysfunction in all studies population

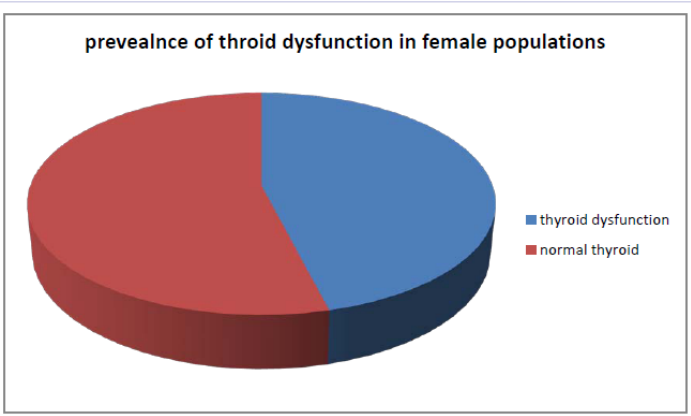

Figure 3: prevealnce of throid dysfunction in female populations.

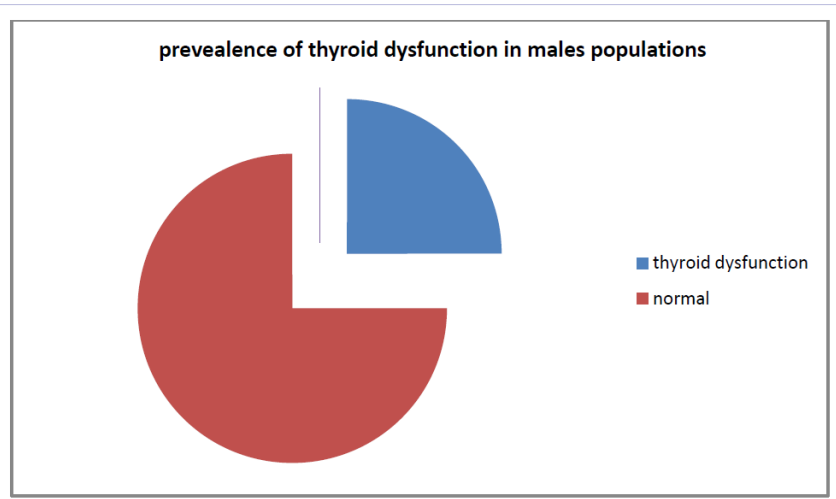

Figure 4: prevealence of thyroid dysfunction in males populations. 
this result agreed with result in literature that females have high risk of hypothyroidisms than males it is ten times in females than males ${ }^{5}$.the prevalence of hyperthyroidisms is $2.8 \%$ our result agreed with another study which express the prevalence of hyperthyroidism between 0.5 to $2 \%$ [5],our all result isn't consider as truly prevalence of hpo and hyperthyroidisms because low sample size and as research rules health center and hospitals based study not give true prevalence of any diseases because not all community or participant have equal choice to participate in the study, but our study give background to high prevalence of hypothyroidisms in albahah this may be due to low iodine intake or high altitude and low iron due to demand of hemoglobin as in literature.

\section{Limitations}

Limitation of this study is partly due to the small size sample and being confined to only one health center which did not underestimate over all prevalence in community, Also the study is not consider as prevalence in all community of albahah .

\section{Conclusions}

Thyroid dysfunction is highly prevalent in albaha city in females more prevalent than males we recommend more researches in this area with high sample size especially in females.

\section{Acknowledgements}

The author's would like to thank ashfa medical complex team for their support especially BABIKER ALSALEH MAHMOUD computer department.

\section{References}

1. Okosieme OE, Marx $\mathrm{H}$, Lazarus JH. Medical management of thyroiddysfunction in pregnancy and the postpartum. Expert Opin Pharmacother. 2008;9(13):2281-2293. doi: 10.1517/14656566.9.13.2281.

2. Vanderpump MPJ. The epidemiology of thyroid diseases.In Braverman LE, Utiger RD, eds. Werner and Ingbar's The Thyroid: A Fundamental and Clinical Text. JB Lippincott-Raven, Philadelphia. 2005;9:398-406.

3. Zimmermann MB, Jooste PL, Pandav CS. Iodine-deficiency disorders. Lancet. 2008; 372(9645):1251-1262. doi: 10.1016/S01406736(08)61005-3.

4. VanderpumpMPJ. Epidemiology of Thyroid Dysfunction Hypothyroidism and Hyperthyroidism; thyroid international. 2009;:4.

5. Tunbridge WMG, Evered DC, Hall R, Appleton D, BrewisM, Clark F, et al.The spectrum of thyroid disease in the community: the Whickham survey. Clin Endocrinol. 1977; 7(6):481-493.

6. Canaris GJ, Manowitz NR, Mayor G, Ridgway EC. The Colorado Thyroid Disease Prevalence Study. ArchIntern Med. 2000;160(4):526-534.

7. Hollowell JG, Staehling NW, Flanders WD, Hannon WH,Gunter EW, Spencer CA, et al. Serum TSH,T4, and thyroid antibodies in the United States population (1988 to 1994): National Health and Nutrition Examination Survey (NHANES III). J Clin Endocrinol Metab. 2002; 87(2):489-499.

8. Awad Saad Al Shahrani, AshrafEl-Metwally, Khaled Al-Surimi, Salih Bin Salih, Yousef Saleh, Abeer Al-Shehri et al. The epidemiology of thyroid diseases in the Arab world: A systematic review. J. Public Health Epidemiol. 2016; Vol. 8(2):17-26. DOI: 10.5897/JPHE2015.0713.

9. "Climate Data for Saudi Arabia". Jeddah Regional Climate Center. Retrieved January 26, 2016.

10. Lamfon HA .Thyroid Disorders in Makkah, Saudi Arabia. OzeanJ. Appl. Sci. 2008;1(1):52-58. 